\title{
Effects of $\mathrm{MgO}$ on dielectric properties and electrical conductivity of ternary zinc magnesium phosphate glasses.
}

\begin{abstract}
Glasses with composition $(\mathrm{ZnO}) 30(\mathrm{MgO}) \mathrm{x}(\mathrm{P} 2 \mathrm{O} 5) 70-\mathrm{x}(\mathrm{ZnO}) 30(\mathrm{MgO}) \mathrm{x}(\mathrm{P} 2 \mathrm{O} 5) 70-\mathrm{x}(\mathrm{x}=5,8$, 13,18 and $20 \mathrm{~mol} \%$ ) have been successfully prepared by the melt-quenching technique. The dielectric permittivity $\left(\varepsilon^{\prime} \varepsilon^{\prime}\right)$ and loss factor $\left(\varepsilon^{\prime \prime} \varepsilon^{\prime \prime}\right)$ were measured in the frequency range of $0.01 \mathrm{~Hz}$ to $1 \mathrm{MHz}$ and in the temperature range of 303 to $573 \mathrm{~K}$. From the results, there is evidence of dipolar relaxation occurring between View the MathML source103-106Hz, while at low frequencies, the spectrum is dominated by dc conduction which was manifested by the $1 / \omega 1 / \omega$ slope of the loss factor plot. The value of the relaxing frequency ( $\omega p \omega p$ ) plotted against 1/T1/T shows a single relaxation mechanism with an activation energy of 0.45 $\mathrm{eV}$. The average value of the activation energy for dc conduction was much higher $(1.25 \mathrm{eV})$ suggesting its diffusion movement had encountered more difficult steps than the small displacement changing dipoles. With increasing $\mathrm{MgO}$ concentration, the dielectric permittivity $\left(\varepsilon^{\prime} \varepsilon^{\prime}\right)$, dc conductivity ( $\left.\sigma \mathrm{dc} \sigma \mathrm{dc}\right)$ and dielectric strength $(\Delta \varepsilon \Delta \varepsilon)$ decrease and these were attributed to some of the magnesium ions participated in the glass-forming positions as well as modifiers. At lower temperatures, the complex permittivity plots present a skewed arc with center point lying below the real axis which is a non-Debye characteristic. The empirical data were sufficiently fitted by using the Harviliak-Negami equation. The temperature dependent of the parameter $\alpha \alpha$ is discussed.
\end{abstract}

Keyword: Dielectric properties; Relaxation, Electric modulus; Phosphates; Short-range order. 